\title{
Determination of Phase Transformation for TC21 Ti-Alloy by Dilatometry Method
}

\author{
Ramadan N. Elshaer1, Khaled M. Ibrahim², Azza F. Barakat ${ }^{3}$, Ahmed I. Farahat ${ }^{2}$, \\ Reham R. Abbas ${ }^{4}$
}

${ }^{1}$ Tabbin Institute for Metallurgical Studies, Cairo, Egypt

${ }^{2}$ Central Metallurgical R \& D Institute, Cairo, Egypt

${ }^{3}$ Faculty of Engineering, Helwan University, Cairo, Egypt

${ }^{4}$ Faculty of Engineering, Suez University, Suez, Egypt

Email: ramadan_elshaer@yahoo.com

How to cite this paper: Elshaer, R.N., Ibrahim, K.M., Barakat, A.F., Farahat, A.I. and Abbas, R.R. (2019) Determination of Phase Transformation for TC21 Ti-Alloy by Dilatometry Method. Open Journal of Metal, 9, 1-10.

https://doi.org/10.4236/ojmetal.2019.91001

Received: February 28, 2019

Accepted: March 28, 2019

Published: March 31, 2019

Copyright (C) 2019 by author(s) and Scientific Research Publishing Inc. This work is licensed under the Creative Commons Attribution International License (CC BY 4.0).

http://creativecommons.org/licenses/by/4.0/

\begin{abstract}
The $\alpha+\beta \leftrightarrow \beta$ phase transformation kinetics of TC21 Ti-alloy during continuous heating and cooling were studied using a dilatometric technique. Dilatometric heating curve exhibited that two characteristic reflection points can be observed with increasing the heating temperature. $\mathrm{T}_{\mathrm{s}}$ referred to the initial transformation temperature of $\alpha+\beta \rightarrow \beta$ and $\mathrm{T}_{\mathrm{f}}$ referred to the final transformation temperature of $\alpha+\beta \rightarrow \beta$. $\mathrm{T}_{\mathrm{s}}$ was reported at $720^{\circ} \mathrm{C}$, whereas the corresponding $\mathrm{T}_{\mathrm{f}}$ was obtained at $950^{\circ} \mathrm{C}$. The initial and final transforming temperatures by the first derivative curve were reported at $730^{\circ} \mathrm{C}$ and $955^{\circ} \mathrm{C}$, respectively, which are close to the values obtained in the dilatometric heating curve. Dilatometric cooling curve showed that the starting temperature of $\beta \rightarrow$ $\beta+\alpha$ phase transformation was $880^{\circ} \mathrm{C}$; however, the corresponding finishing temperature was $670^{\circ} \mathrm{C}$. The starting and finishing temperatures using the first derivative curve were obtained at $665^{\circ} \mathrm{C}$ and $885^{\circ} \mathrm{C}$, respectively. The first derivative for the studied dilatometric heating and cooling curves showed that the starting and finishing temperatures of $\alpha+\beta \leftrightarrow \beta$ phase transformation were more accurate and objective. Results show the $\alpha+\beta \rightarrow \beta$ transformation heating curve exhibits a typical S-shaped pattern.
\end{abstract}

\section{Keywords}

TC21 Ti-Alloy, Phase Transformation, Dilatometry, Heating, Cooling

\section{Introduction}

TC21 (Ti-6Al-2Sn-2Zr-3Mo-1Cr-2Nb-Si, wt.\%) alloy was developed as a high strength, toughness, damage tolerance and low crack propagation rate and pro- 
vides weight reduction, long service life, and high reliability in fabricated aircraft structural components such as frames and beams [1] [2]. The $\beta$ transus temperature for an alloy is very significant for heat-treating purposes, especially when heat treatment involves heating near or above the $\beta$ transus. The transformation from $\alpha$ to $\beta$ phase is very dependent on the purity of the titanium [3] [4].

Dilatation behavior of metals depends on the thermal change of length as a function of temperature. When titanium alloys heated to $\beta$ transus temperature, the change in volume will be affected by crystal structure changing from hexagonal close-packed to body-centered cubic as well as solute atom redistribution. In addition, titanium alloys possess apparent similarities to steels in terms of $\alpha+$ $\beta \rightarrow \beta$ phase transformation during continuous heating [5] [6]. The phase transformation of TC21 Ti-alloy is sensitive to aging temperature and heating history [5] [7]. Due to the presence of thermal expansion misfit of various phases, dilatometry method has been successfully used to discuss the $\omega$ phase formation in metastable $\beta$ Ti-based alloys [8] and orthorhombic martensite decomposition in TC21 titanium alloy [5] as well as $₫$ phase transformation of Ti-7333 titanium alloy during continuous heating [9].

The dilatometric technique is commonly employed to analyze the kinetics of solid-state phase transformation [10] [11]. This technique was also successfully used by Wan et al. [11] to study the activation energy for $\alpha+\beta \rightarrow \beta$ transformation in Ti-1300 alloy and by Sun et al. [12] to discuss the phase transformation kinetics in Ti60 alloy during continuous cooling as well as by Wang et al. [13] to investigate the $\alpha+\beta \rightarrow \beta$ transformation in Ti55531 alloy during continuous heating. Based on the dilatometry curves, Wan et al. [11] found that the curves of the $\alpha+\beta \rightarrow \beta$ phase transformation exhibited a typical S-shaped pattern, which indicated that $\alpha+\beta \rightarrow \beta$ phase transformation is a nucleation-growth-controlled process. However, rarely studies were conducted the $\alpha+$ $\beta \leftrightarrow \beta$ phase transformation during continuous heating and cooling. Therefore, the present study aimed to investigate the $\alpha+\beta \leftrightarrow \beta$ phase transformation kinetics of TC21 Ti-alloy during continuous heating and cooling.

\section{Experimental Work}

TC21 Ti-alloy was received as bars of $7 \mathrm{~mm}$ diameter and $140 \mathrm{~mm}$ length. The chemical composition of the alloy analyzed by inductive coupled plasma-atomic emission spectrometry (ICP-AES) is listed in Table 1. The original microstructure (Figure 1) of as-received TC21 Ti-alloy consists of primary equiaxed $\alpha$ phase which was uniformly distributed in the transformed $\beta$ matrix. The average grain size of equiaxed $\alpha$ phase was approximately $2.5 \mu \mathrm{m}$ and their volume fraction approached to $65 \%$ using image analyzer. The XRD pattern confirmed the presence of $\alpha$ and $\beta$ phase in as-received TC21 Ti-alloy, Figure 2. It is noticed that $\beta$ peaks are rather weak, suggesting a relatively low volume fraction of the $\beta$-phase $(\approx 35 \%)$.

A dilatometer attached with a computer-controlled horizontal pushrod dilatometer (LINSEIS DIL L76 instrument, Germany), was used for measuring the 
Table 1. Chemical composition of as-received TC21 Ti-alloy (mass fraction, \%).

\begin{tabular}{ccccccccccccc}
\hline $\mathrm{Al}$ & $\mathrm{Mo}$ & $\mathrm{Nb}$ & $\mathrm{Sn}$ & $\mathrm{Zr}$ & $\mathrm{Cr}$ & $\mathrm{Si}$ & $\mathrm{Fe}$ & $\mathrm{C}$ & $\mathrm{N}$ & $\mathrm{H}$ & $\mathrm{O}$ & $\mathrm{Ti}$ \\
\hline 6.5 & 3.0 & 1.9 & 2.2 & 2.2 & 1.5 & 0.09 & 0.05 & 0.01 & 0.01 & 0.001 & 0.07 & Bal. \\
\hline
\end{tabular}
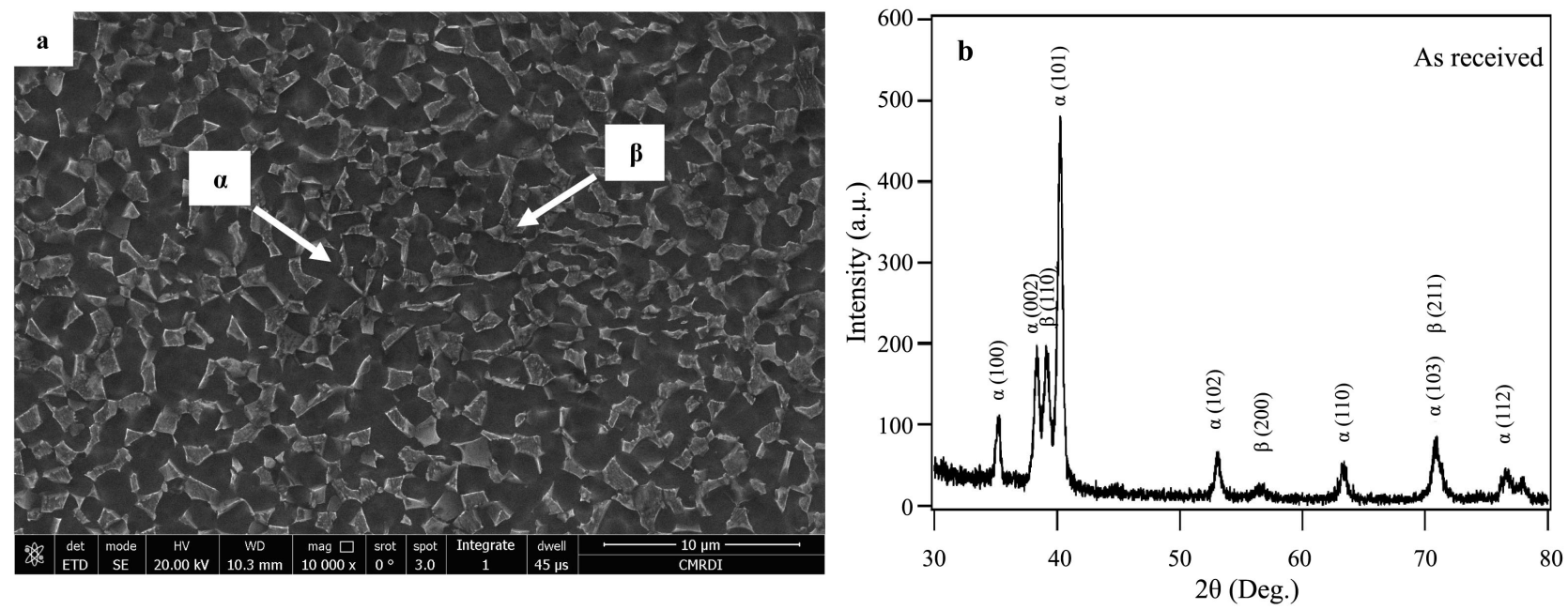

Figure 1. FESEM micrograph of TC21 Ti-alloy (a) and XRD pattern of TC21 Ti-alloy (b).

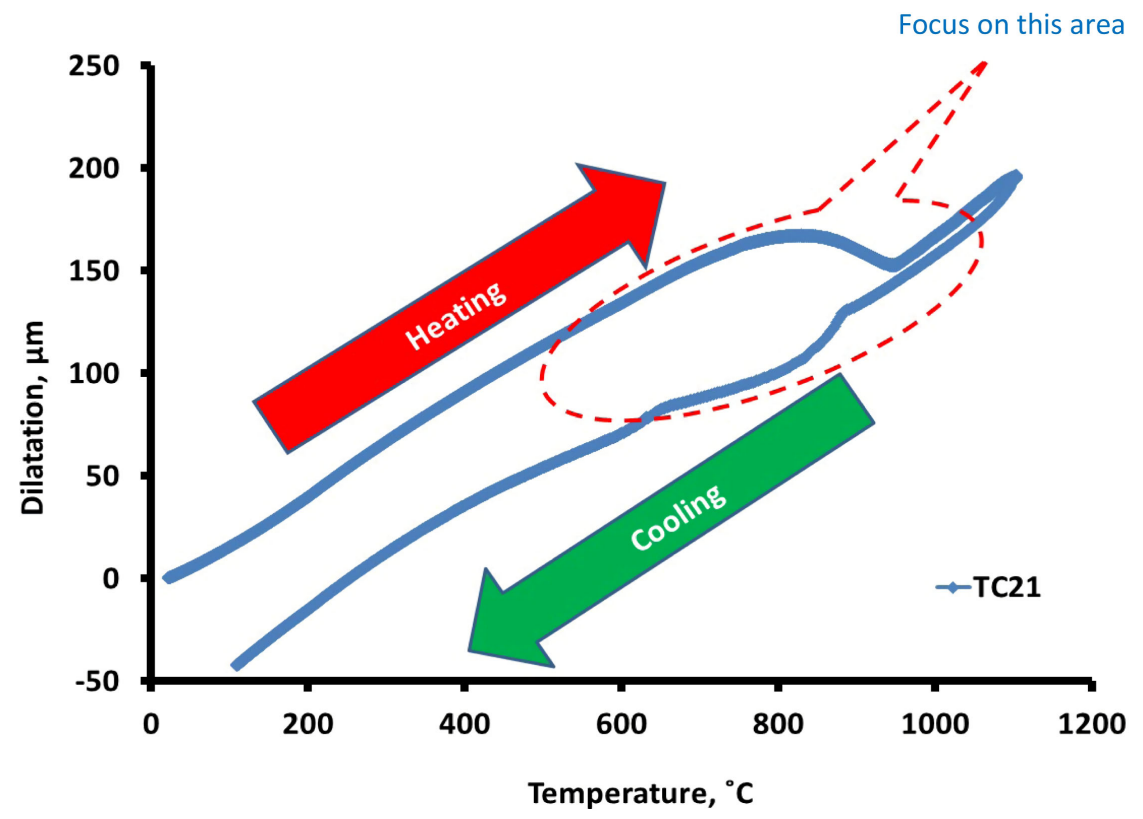

Figure 2. General view of a dilatometric curve for TC21 Ti-alloy.

during continuous heating and cooling. Sample of diameter $4 \mathrm{~mm}$ and $20 \mathrm{~mm}$ length was precisely machined using wire electrical discharge machine (EDM). The sample was placed in contact with the pushrod and heated at a rate of $10^{\circ} \mathrm{C} / \mathrm{min}$ up to $1100^{\circ} \mathrm{C}$ in static air, and then the sample cooled in air down to room temperature. Change in sample length with temperature was recorded using WIN-DIL software. The first derivative was determined using equation between temperature and length to determine the $\alpha+\beta \leftrightarrow \beta$ phase transformation 
temperature for the as-received material. The metallographic samples were heated at a normal heat treatment furnace at the heating rate of $10 \mathrm{k} / \mathrm{min}$, and then water quenched at different temperature. The microstructures were observed by field emission scanning electron microscopy (FESEM). The samples for FESEM were prepared by rough and fine mechanical polishing followed by etching with a solution consisting of $3 \% \mathrm{HF}, 30 \% \mathrm{HNO}_{3}$ and $67 \% \mathrm{H}_{2} \mathrm{O}$.

\section{Results and discussion}

\subsection{Dilatometric Analysis}

Figure 2 shows an example for the general view of a dilatometric curve (compression/dilation as a function of temperature) obtained during heating and cooling of a sample of TC21 Ti-alloy. Transformation temperatures are determined from the slope changes in the curve that denoted to the change in sample length.

By heating the sample above $720^{\circ} \mathrm{C}$ (Point A in Figure 3), the curve started to be non-linear. In such case, the curve reaching a certain peak at $830^{\circ} \mathrm{C}$ and then goes down till $950^{\circ} \mathrm{C}$. This could be attributed to the shrinking influence caused by crystal structure changing from duplex $(\alpha+\beta)$ structure into a single structure of $\beta$ phase [11] [14]. As the $\alpha+\beta \rightarrow \beta$ phase transformation continues, the sample continuously shrinks and then finally stops at $950^{\circ} \mathrm{C}$ (Point B in Figure 3 ). As the temperature continues to increase, the length of the sample starts to increase and becomes linear due to stopping the $\alpha+\beta \rightarrow \beta$ phase transformation with further increase in temperature.

At $720^{\circ} \mathrm{C}$ (Point $\mathrm{A}$ in Figure 3), the amount of $\alpha$ phase achieved the maximum. This means that there will be an equilibrium state between $\alpha$ and $\beta$ phases

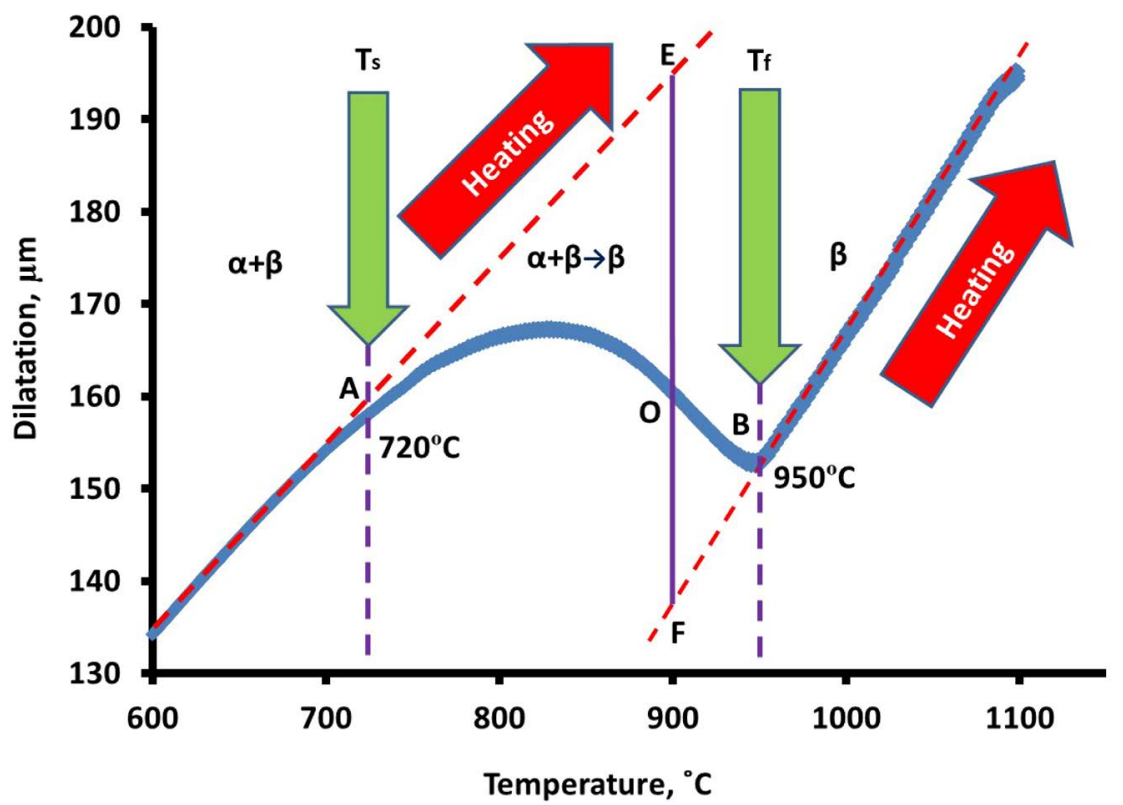

Figure 3. Dilatometric heating curve for starting and finishing temperatures of $\alpha+\beta \rightarrow \beta$ phase transformation. 
at this temperature. When the temperature obtains higher than $720^{\circ} \mathrm{C}$, the equilibrium will be broken, and $\alpha$ phase will be transformed to $\beta$ phase. Then, the ratio of $\beta$ to $\alpha$ increases and the expansion of the phase dominates the overall expansion of the alloy. As a result, a relative increase in sample length will be observed on the dilatometric curve until the $\beta$ transus $\left(950^{\circ} \mathrm{C}\right)$. With further increase in temperature more than $\beta$ transus, $\mathrm{T}_{\beta}\left(950^{\circ} \mathrm{C}\right)$, a complete $\beta$ phase will be formed. Two characteristic reflection points can be observed in the above mentioned dilatometric curve with increasing the heating temperature. They are defined as $\left(\mathrm{T}_{\mathrm{s}}\right)$ which referred to starting transformation temperature of $\alpha+\beta \rightarrow$ $\beta$ and $\left(\mathrm{T}_{\mathrm{f}}\right.$ ) finishing transformation temperature of $\alpha+\beta \rightarrow \beta$. $\mathrm{T}_{\mathrm{s}}$ for the investigated TC21 Ti-alloy was reported at $720^{\circ} \mathrm{C}$, whereas the corresponding $\mathrm{T}_{\mathrm{f}}$ was obtained at $950^{\circ} \mathrm{C}$.

In addition, the first derivative for the studied dilatometric heating curve showed that starting and finishing temperatures of the $\alpha+\beta \rightarrow \beta$ phase transformation were more accurately and objectivity, Figure 4 . The started and finished transforming temperatures using the first derivative curve (Figure 4) were reported at $730^{\circ} \mathrm{C}$ and $955^{\circ} \mathrm{C}$, respectively, which are close to the values obtained in the dilatometric heating curve $\left(720^{\circ} \mathrm{C}\right.$ and $\left.950^{\circ} \mathrm{C}\right)$.

Studying phase transformation kinetics during continuous cooling from both $\alpha+\beta$ range and $\beta$ range is essential if the material is to be properly processed [11]. Dilatometric cooling curve for TC21 Ti-alloy from $\beta$ range $\left(1100^{\circ} \mathrm{C}\right)$ using cooling air is shown in Figure 5. The starting temperature of $\beta \rightarrow \beta+\alpha$ phase transformation was $885^{\circ} \mathrm{C}$; however, the corresponding finishing temperature was $665^{\circ} \mathrm{C}$. These temperatures are smaller than the observed in heating, motivated by the transformation $\beta \rightarrow \beta+\alpha$. It is clear that during the heating process, the volume shrinks as the sample transform from the $\alpha+\beta$ phase to $\beta$ phase, and the volume increases when cooled. These results were in agreement with previous results [11] [14]. Figure 6 describes the first derivative for dilatometric

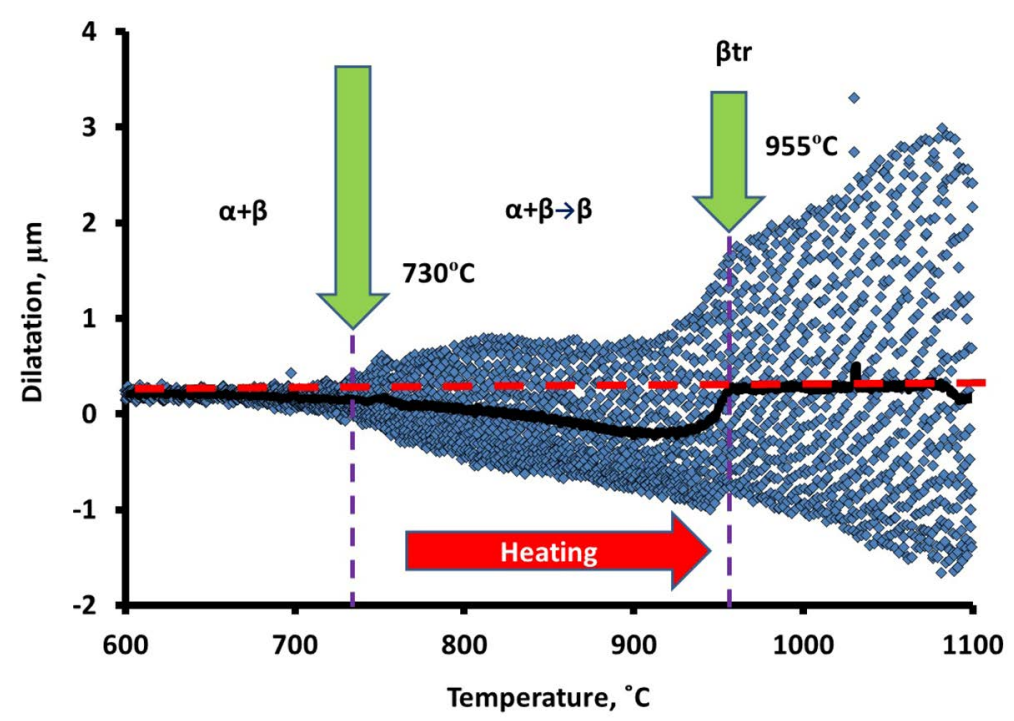

Figure 4. First derivative for dilatometric heating curve. 


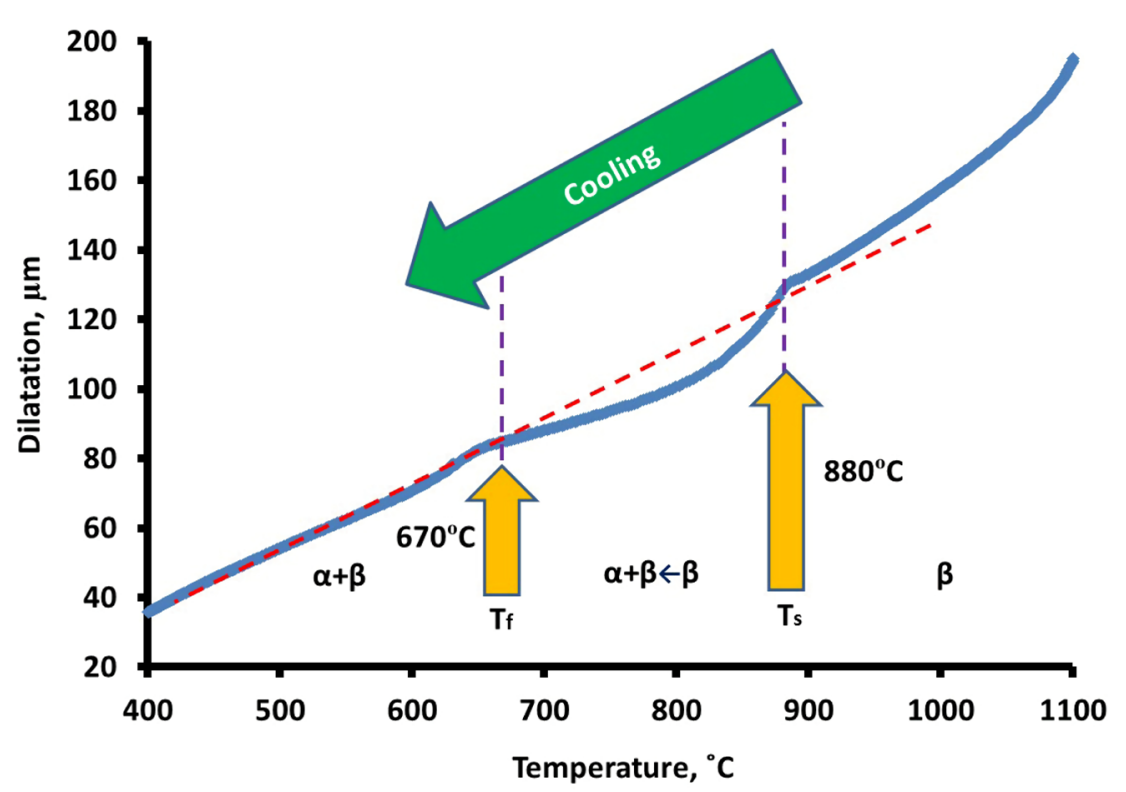

Figure 5. Dilatometric cooling curve for starting and finishing temperatures of the $\beta \rightarrow \beta$ $+\alpha$ phase transformation.

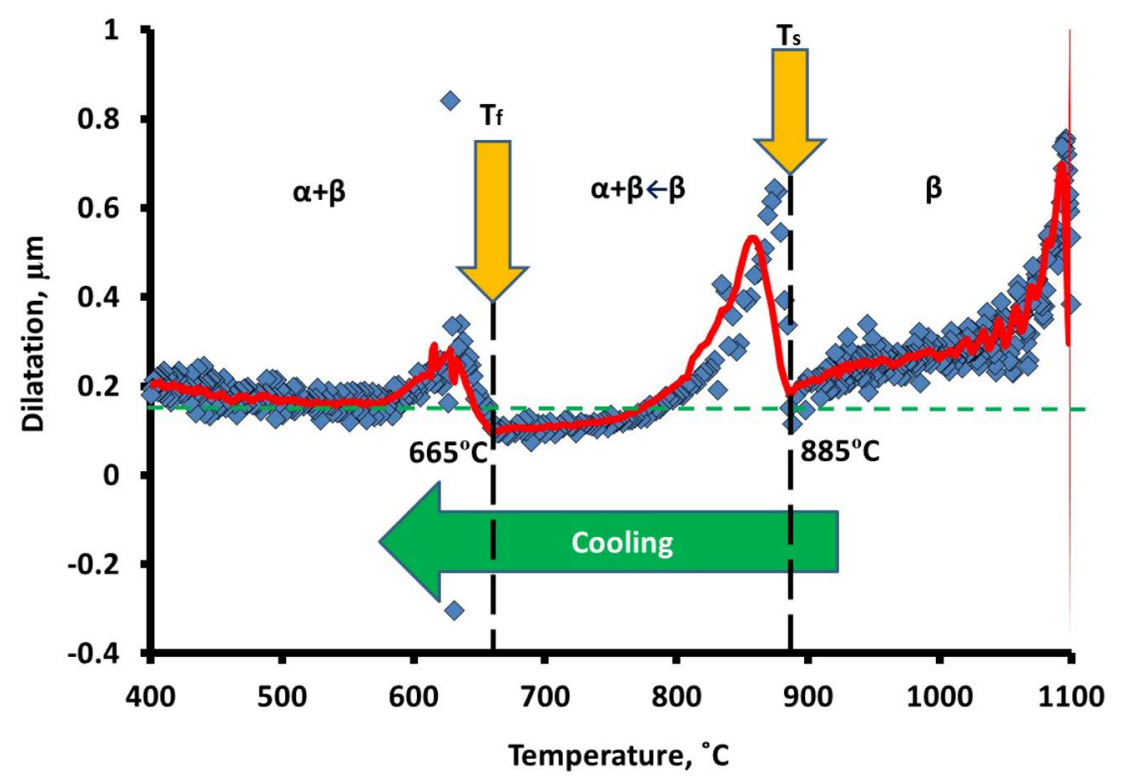

Figure 6. First derivative for dilatometric cooling curve.

cooling curve. The starting and finishing temperatures were obtained at $665^{\circ} \mathrm{C}$ and $885^{\circ} \mathrm{C}$, respectively. It is found that the starting and finishing temperatures of $\beta \rightarrow \beta+\alpha$ phase transformation were more accurately and objectivity.

\subsection{Determination of $\alpha+\beta \rightarrow \beta$ Phase Transformation Fraction}

The $\alpha+\beta \rightarrow \beta$ phase transformation fraction is used to reflect the $\alpha+\beta \rightarrow \beta$ phase kinetics during continuous heating. The dilatation characteristics of titanium alloy, which is a polycrystalline material, can be isotropic in the solid-state phase transformation [11] [14]. Thus, the relationship between variation in vo- 
lume $\left(\Delta V / V_{o}\right)$ and relative length $\left(\Delta L / L_{o}\right)$ in the solid-state phase transformation process can be expressed as [11]:

$$
\left(\Delta V / V_{o}\right)=3\left(\Delta L / L_{o}\right)
$$

where $L_{o}$ is the original sample length, $V_{o}$ is the original sample volume, and $\Delta V$ and $\Delta L$ are the volume and length variations of the sample, respectively. Considering the dilatometric heating curve of the investigated TC21 sample, the degree of deviation degree of the dilatometric curve should be proportional to the $\alpha+\beta \rightarrow \beta$ transformed volume fraction. Therefore, the level rule can be employed to analyze the dilatometric curve to explore the relationship between the $\alpha+\beta \rightarrow \beta$ transformed volume fraction $(f)$ and heating temperature (Figure 3 ).

$$
f=L_{\mathrm{EO}} / L_{\mathrm{EF}}
$$

where $L_{\mathrm{EO}}$ and $L_{\mathrm{EF}}$ are the measuring lengths of $\mathrm{EO}$ and $\mathrm{EF}$ lines representing in Figure 3. Figure 7 shows the $\alpha+\beta \rightarrow \beta$ transformation curve that exhibited a typical S-shaped pattern. This means that the $\alpha+\beta \rightarrow \beta$ phase transformation for the TC21 Ti-alloy is a nucleation-growth-controlled process [7] [15]. This finding was in agreement with the results reported by Wan et al. [11] and Hui et al. [16].

The $\alpha+\beta \rightarrow \beta$ phase transformation in the TC21 Ti-alloy during continuous heating was identified by quenching the samples from different temperatures. Three samples were chosen based on the dilatometric curve measurements. The samples were heated continuously to $830^{\circ} \mathrm{C}, 900^{\circ} \mathrm{C}$ and $1000^{\circ} \mathrm{C}$ and then immediately quenched in water. Figure 8 shows the microstructure feature of the three tested samples. When samples 1 and 2 were heated to $830^{\circ} \mathrm{C}$ and $900^{\circ} \mathrm{C}$, respectively (Figure 8(a) \& Figure 8(b)), the volume fraction of the primary $\alpha$ phase significantly reduces as the heating temperatures increases, but the $\beta$ grain grows gradually. This indicated that the transformation from $\alpha$ to $\beta$ has been obtained.

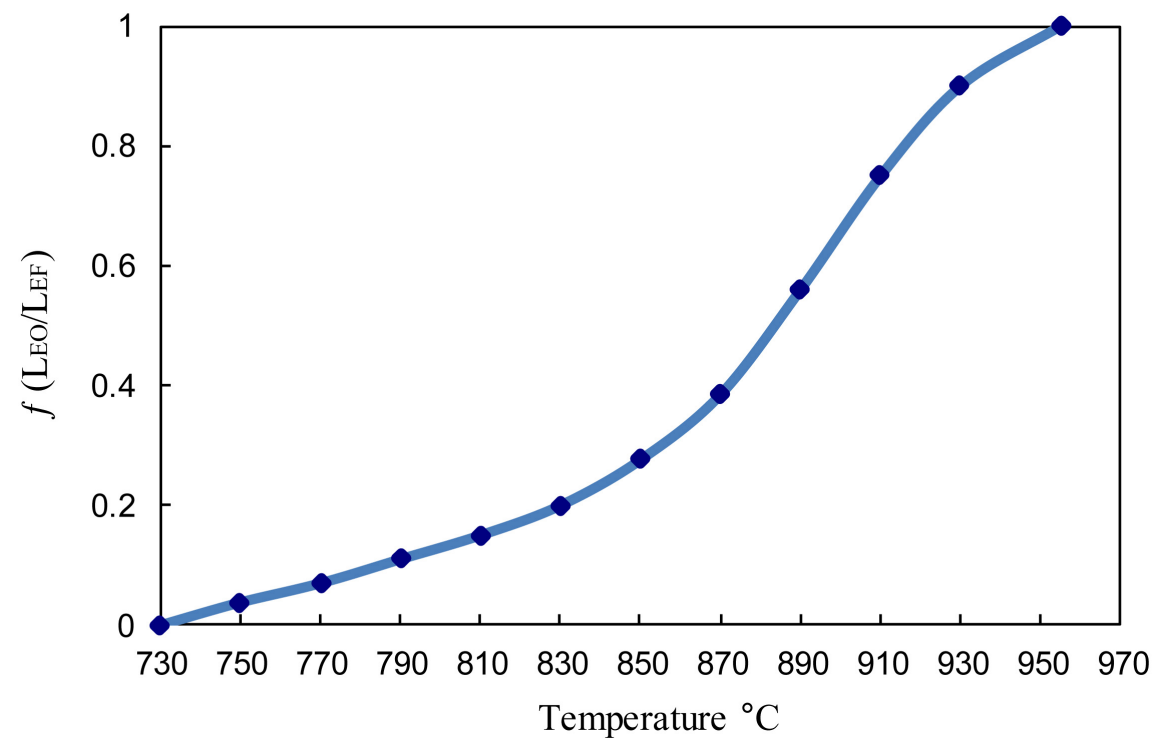

Figure 7. $\alpha+\beta \rightarrow \beta$ phase transformed volume fraction $(f)$ as a function of temperature. 

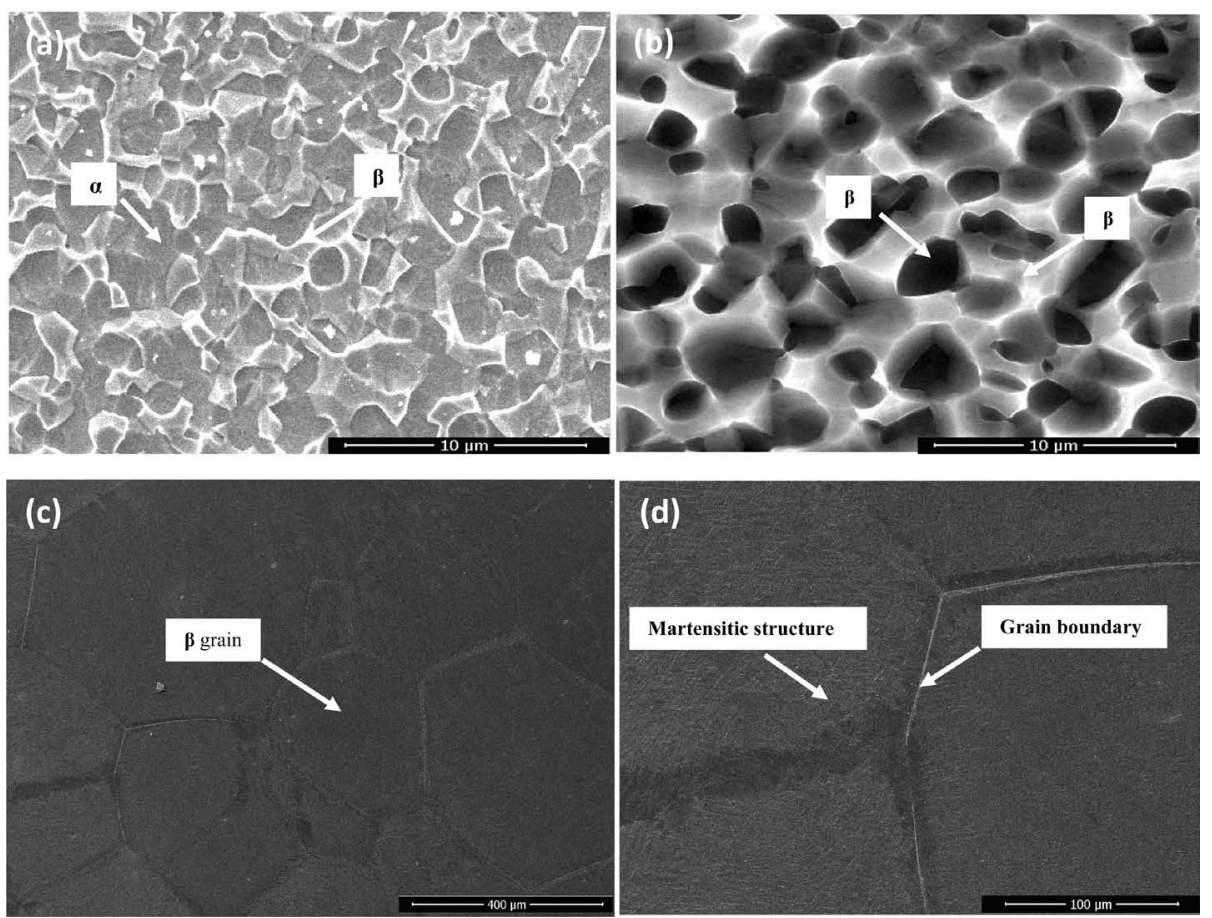

Figure 8. Microstructure of TC21 Ti-alloy after quenching from different temperatures during continuous heating at: (a) 830 , (b) 900 , and (c, d) $1000^{\circ} \mathrm{C}$.

When the temperature was above the $\beta$ transus at $1000^{\circ} \mathrm{C}$ (Figure 8 (c) \& Figure $8(\mathrm{~d})$ ), the whole microstructure has transformed into $\beta$ phase; the quenched microstructure of $\beta$ is a complete martensitic structure. The $\beta$ grain then became very coarse with a grain size of approximately $300 \mu \mathrm{m}$. This result was consistent with a previous study [7] [14].

\section{Conclusions}

From the results related to $\alpha+\beta \leftrightarrow \beta$ phase transformation of TC21 Ti-alloy during continuous heating and cooling, which were effectively studied by dilatometry technique, the following conclusions can be drawn.

1) Dilatometric heating curve showed that starting and finishing temperatures of the $\alpha+\beta \rightarrow \beta$ phase were obtained at $720^{\circ} \mathrm{C}$ and $950^{\circ} \mathrm{C}$, respectively. In addition, the first derivative for heating exhibited that starting and finishing temperatures were reported at $730^{\circ} \mathrm{C}$ and $955^{\circ} \mathrm{C}$, respectively.

2) Dilatometric cooling curve exhibited that the starting temperature of $\beta \rightarrow \beta$ $+\alpha$ phase transformation was $880^{\circ} \mathrm{C}$; however, the finishing temperature was $670^{\circ} \mathrm{C}$. While, the starting and finishing temperatures using the first derivative curve were obtained at $665^{\circ} \mathrm{C}$ and $885^{\circ} \mathrm{C}$, respectively.

3) The first derivative for the studied dilatometric heating and cooling curves showed that starting and finishing temperatures of the $\alpha+\beta \leftrightarrow \beta$ phase transformation were more accurately and objectivity.

4) The $\alpha+\beta \rightarrow \beta$ transformation heating curve of the TC21 Ti-alloy presents a typical S-shaped pattern. 


\section{Conflicts of Interest}

The authors declare no conflicts of interest regarding the publication of this paper.

\section{References}

[1] Elshaer, R.N., Ibrahim, K.M., Barakat, A.F. and Abbas, R.R. (2017) Effect of Heat Treatment Processes on Microstructure and Mechanical Behavior of TC21 Titanium Alloy. Open Journal of Metal, 7, 39-57. https://doi.org/10.4236/ojmetal.2017.73004

[2] Shi, Z., Guo, H., Zhang, J. and Yin, J. (2018) Microstructure-Fracture Toughness Relationships and Toughening Mechanism of TC21 Titanium Ally with Lamellar Microstructure. Transactions of Nonferrous Metals Society of China, 28, 2440-2448.

[3] Lütjering, G. and Williams, J.C. (2007) Titanium. 2nd Edition, Springer, Berlin, Heidelberg, New York.

[4] Banerjee, D. and Williams, J.C. (2013) Perspectives on Titanium Science and Technology. Acta Materialia, 61, 844-879.

[5] Tang, B., Kou, H., Wang, Y., Zhu, Z., Zhang, F. and Li, J. (2012) Kinetics of Orthorhombic Martensite Decomposition in TC21 Alloy under Isothermal Conditions. Journal of Materials Science, 47, 521-529. https://doi.org/10.1007/s10853-011-5829-5

[6] Xiong, C., Xue, P., Zhang, F. and Li, Y. (2017) Phase Transformations and Microstructural Evolution in Ti-19.5Zr-10Nb-0.5Fe Shape Memory Alloys. Material Characterization, 133, 156-164.

[7] Wang, Y.H., Kou, H.C., Chang, H., Zhu, Z.S., Zhang, F.S., Li, J.S. and Zhou, L. (2009) Influence of Solution Temperature on Phase Transformation of TC21 Alloy. Materials Science and Engineering A, 508, 76-82.

[8] Zhou, Z., Lai, M., Tang, B., Kou, H., Chang, H., Zhu, Z., Li, J. and Zhou, L. (2010) Non-Isothermal Phase Transformation Kinetics of $\omega$ Phase in TB-13 Titanium Alloys. Materials Science and Engineering A, 527, 5100-5104.

[9] Hui, Q., Xue, X., Kou, H., Lai, M., Tang, B. and Li, J. (2013) Kinetics of the $₫$ Phase Transformation of Ti-7333 Titanium Alloy during Continuous Heating. Journal of Materials Science, 48, 1966-1972. https://doi.org/10.1007/s10853-012-6962-5

[10] Zhu, T.K. and Li, M.Q. (2011) Effect of Hydrogen on the $\beta$ Transus Temperature of TC21 Alloy. Materials Characterization, 62, 852-856. https://doi.org/10.1016/j.matchar.2011.06.003

[11] Wan, M.-P., Zhao, Y.-Q. and Zeng, W.-D. (2015) Phase Transformation Kinetics of Ti-1300 Alloy during Continuous Heating. Rare Metals, 34, 233-238. https://doi.org/10.1007/s12598-015-0472-y

[12] Sun, F., Li, J., Kou, H., Tang, B., Chen, Y., Chang, H. and Cai, J. (2013) Phase Transformation Kinetics in Ti60 Alloy during Continuous Cooling. Journal of Alloys and Compounds, 576, 108-113. https://doi.org/10.1016/j.jallcom.2013.04.117

[13] Wang, G., Zang, X., Li, Z. and Zhou, K. (2014) Phase Transformation of Ti55531 Alloy during Continuous Heating Process. Journal of Nonferrous Metals, 24, 1771-1777.

[14] Wang, Y., Kou, H., Chang, H., Zhu, Z., Su, X., Li, J. and Zhou, L. (2009) Phase Transformation in TC21 Alloy during Continuous Heating. Journal of Alloys and Compounds, 472, 252-256. https://doi.org/10.1016/j.jallcom.2008.04.035 
[15] Chen, H. and Cao, C. (2012) Characterization of Hot Deformation Microstructures of Alpha-Beta Titanium Alloy with Equiaxed Structure. Transactions of Nonferrous Metals Society of China, 22, 503-509.

https://doi.org/10.1016/S1003-6326(11)61205-3

[16] Davari, N., Rostami, A. and Abbasi, S.M. (2017) Effects of Annealing Temperature and Quenching Medium on Microstructure, Mechanical Properties as well as Fatigue Behavior of Ti-6Al-4V Alloy. Materials Science \& Engineering A, 683, 1-8. https://doi.org/10.1016/j.msea.2016.11.095 